electro-optical effects, namely, anomalous birefringence and dichroism near the lines which appear in both polarisations shifted or with different intensity. We have investigated these effects by putting the absorbing layer between crossed ultra-violet nicols placed with the axis at $45^{\circ}$ to the electric field. With such an arrangement we observed an emission spectrum corresponding to the lines which are different in both polarisations. With this apparatus it is impossible to distinguish between dichroism and birefringence. This investigation will be carried on with a more appropriate method.

Further details, theoretical and experimental, will be published shortly.

Institute of Physics,

EdOARDo AmaLdi. EMmLio Segrè.

University,

Rome.

July 17.

${ }^{1}$ Proc. Amst., 35, $589 ; 1933$.

\section{Poisson Series and Biological Data}

IT has been observed that the powder-post beetles Lyctus linearis and $L$. brunneus do not deposit a constant number of eggs in each vessel they attack, and observations have been made by one of us (E. A. P.) on the frequency with which given numbers of eggs are laid by these insects in the vessels of English oak.

As shown in Tables I and II, the observed frequencies agree closely with Poisson series having means 0.84 and 1.85 respectively.

\section{GROUPING OF EGGS OF LYCTUS IN VESSELS OF ENGLISH OAK \\ TABLE I.}

L. linearis.

\begin{tabular}{|c|c|c|c|}
\hline $\begin{array}{c}\text { No. of eggs } \\
\text { per group }(n) .\end{array}$ & $\begin{array}{c}\text { Observed } \\
\text { frequency. }\end{array}$ & $\begin{array}{c}(n-1) \times \\
\text { frequency. }\end{array}$ & $\begin{array}{c}\text { Calculated } \\
\text { frequency. }\end{array}$ \\
\hline 1 & 121 & 0 & 120 \\
2 & 98 & 98 & 100 \\
3 & 45 & 90 & 42 \\
4 & 14 & 42 & 12 \\
5 & 1 & 4 & 2 \\
\hline
\end{tabular}

Mean $0 \cdot 84$

L. brunneus.

TABLE II.

\begin{tabular}{|c|c|c|c|}
\hline $\begin{array}{c}\text { No. of eggs } \\
\text { per group }(n) .\end{array}$ & $\begin{array}{c}\text { Observed } \\
\text { frequency. }\end{array}$ & $\begin{array}{c}(n-1) \times \\
\text { frequency. }\end{array}$ & $\begin{array}{c}\text { Calculated } \\
\text { frequency. }\end{array}$ \\
\hline 1 & 29 & 0 & 28 \\
2 & 42 & 42 & 52 \\
3 & 60 & 84 & 48 \\
4 & 28 & 52 & 29 \\
5 & 13 & 25 & 14 \\
6 & 5 & 0 & 5 \\
7 & 0 & 7 & 0 \\
\hline & 1 & & \\
\hline
\end{tabular}

This difference of unity between the means indicates that $L$. brunneus on the average lays one more egg per vessel than $L$. linearis. Further information is desirable before formulating possible explanations of this, so no attempt is made to do so.

It is desired to direct attention not only to the difference between the two species but also to the method of obtaining the series. A Poisson series must have classes ranging from zero occurrences upwards. The data in question cannot, from their nature, have a class of zero eggs per group, so that the lowest class must be taken as the zero class. In other words, the frequency of occurrence of more than one egg per group is examined. Thus, in column 3 of the Tables, $n-1$ is used instead of $n$ for calculation of the mean. Similarly, if in any set of observations for some reason the class of one per group could not exist, it would be justifiable to use $n-2$ to calculate the mean.

It must be emphasised, however, that there must be reasons, or suspected reasons, for the zero class not existing. It is not sufficient for it not to be observed, for it might, in the size of sample taken, have an expected frequency of zero.

The value of analysing the data in this way is first that the sampling technique is tested and secondly that differences in the means of different samples may be tested for significance.

A similar device was employed in studying the grouping of the vessels of Munyama (Khaya anthotheca). In this wood the vessels occur solitarily or in short radial groups. Here, again, a zero class does not exist, so that the frequency of occurrence of more than one vessel per group was examined.

Once a sufficient number of observations has proved the significance of differences between species, the mean may be used for identification of species, though in the case of the egg groups, the labour involved and the existence of other tests detract from its value for this purpose. There must be many other biological observations to which a similar method of analysing the data would apply.

E. D. VAN REST.

E. A. Parkin.

Forest Products Research Laboratory, Princes Risborough. July 28.

\section{Translation of 'Luftkörper'}

THw expression 'air-mass' is, I believe, now universally employed in English as the equivalent of the German term 'Luftkörper', applied to extensive masses of air that, according to the conceptions developed by the Bergen school of meteorologists, are approximately homogeneous horizontally and tend to retain their distinctive characteristics in moving over the earth.

In Dr. Kassner's "Meteorologisches Wörterbuch", which forms a valuable feature of the recently published second volume of the "Meteorologisches Taschenbuch", edited by Dr. F. Linke, I find this expression rendered "atmospheric body" in the list of English equivalents. Although, as indicated in the "Taschenbuch", I collaborated with Dr. Kassner in preparing the English part of this glossary, the term 'Luftkörper' was not included in the list of German terms that he sent to me for translation, and I am therefore not responsible for the rendering above mentioned.

Dr. Kassner is entitled to the gratitude of all meteorologists for the publication of this tri-lingual glossary, which will doubtless be helpful in standardising meteorological terminology, and will serve as a valuable supplement to the list of equivalent terms in ten languages published in the "Meteorological Glossary" of the Meteorological Office (second edition).

Library, Weather Bureau, C. F. Talman. Aug. 2. 